\title{
Fixation of Lateral Humeral Condyle by Screw in Children
}

\author{
Abd Elhakim Abd Allah Farag, Galal Mohamed Mansour Hegazy, Islam Ahmed Mohamed El \\ Sharnoby
}

Department of Orthopedic, Faculty of Medicine, Al-Azhar University

\begin{abstract}
Background: fractures of the lateral condyle of the humerus represent the second most common type of fracture of the elbow in children. Although this injury is seen at all ages, it is predominately observed in children aged between 5 and 10 years. These injuries are typically the result of an avulsion of a portion of the humeral condyle by pull of the extensor musculature due to a varus force on a supinated forearm or by the direct force of the radial head onto the condyle in the setting of a fall and axial load through an extended elbow.

Objective: the purpose of this study was to evaluate the results of fixation of lateral humeral condyle by screw in children by assessment of time to full union, range of motion, and percentage of complications according to Hardacre criteria.

Patients and Methods: a randomized prospective interventional study aiming at evaluating of open reduction and fixation of lateral humeral condyle by screw. Our series was conducted in Wadi El- Natroun hospital in the period from February 2017 to December 2017; 15 patients with pediatric lateral condyle fractures cases operated with open reduction internal fixation by partially serrated $4.0 \mathrm{o}$. Mean follow up was 6.8 months.

Results: we compared our results with the results of the studies in literature, which used screw fixation in management of pediatric lateral condyle fracture.

Conclusion: the current follow-up is insufficient to determine whether growth disturbance may be problematic. One other important consideration when screw fixation is utilized is the additional cost of a secondary procedure for screw removal and the medulla of children is small which may lead to the screw crosses the olecranon fossa.
\end{abstract}

Keywords: Fixation, Lateral, Humeral Condyle

\section{INTRODUCTION}

Fractures of the lateral condyle of the humerus represent the second most common type of fracture of the elbow in children. Although this injury is seen at all ages, it is predominately observed in children aged between 5 and 10 years ${ }^{(1)}$.

These injuries are typically the result of an avulsion of a portion of the lateral humeral condyle by pull of the extensor musculature due to a Varus force on a supinated forearm (Milch type II) or by the direct force of the radial head onto the lateral condyle in the setting of a fall and axial load through an extended elbow (Milch type I) ${ }^{(2)}$.

Multiple treatment options are available for these fractures, ranging from simple immobilization for nondisplaced or minimally displaced fracture patterns, to Operative reduction and fixation with Kirschner wires (K-wires) or screws for displaced fractures. Although some controversy exists with regard to the acceptable amount of displacement, fractures with displacement greater than $2 \mathrm{~mm}$ or $3 \mathrm{~mm}$ are generally thought to require open reduction and fixation to facilitate union and prevent deformity and articular incongruity. Because of concerns about the possibility of loss of fixation with brief use of $\mathrm{K}$ wires or occurrence of infection with their prolonged use, authors have explored the use of screw fixation for lateral condyle fractures. In theory, screws should be better suited for resisting load in tension, provide more stable fixation, resulting in a higher union rate, with decreased duration of casting (possibly leading to an improved range of motion) ${ }^{(3)}$.

\section{AIM OF THE WORK}

The purpose of this study is to evaluate the results of fixation of lateral humeral condyle by screw in children by assessment of time to full union, range of motion, and percentage of complications according to Hardacre criteria.

\section{PATIENTS AND METHODS}

Study design: A randomized prospective interventional study aiming at evaluating of open reduction and fixation of lateral humeral condyle by screw. Our series was conducted in Wadi El-Natroun hospital in the period from February 2017 to December 2017; 15 patients with pediatric lateral condyle fractures cases operated with open reduction internal fixation by partially serrated $4.0 \mathrm{o}$. Mean follow up was 6.8 months. The study was approved by the Ethics Board of Al-Azhar University.

\section{Patients' selection:}

Inclusion criteria: Pediatrics and children up to 12 years with lateral condyle humerus fracture, and males and females.

Exclusion criteria: 1 . Children up to 8 years with supracondylar humerus fracture, 
transphyseal condyle fracture and medial condyle humerus fractures. 2. Pathological fractures. 3. Open fractures.

Sample size: The study contained 15 patients who met the inclusion criteria. All patients were followed prospectively for minimum of 6 months.

\section{RESULTS}

\section{Time to full union: (in weeks)}

We noted that time to full union was minimum 6 weeks; maximum was 14 weeks with a mean time was 8.5 weeks which is not significant statistically.

Table (1): Frequencies statistics according to time needed to full union.

\begin{tabular}{|l|c|c|}
\hline \multicolumn{1}{|c|}{ Time } & Frequency & Percent \\
\hline 6 weeks & 4 & 26.6 \\
\hline 8 weeks & 3 & 20 \\
\hline 9 weeks & 3 & 20 \\
\hline 11 weeks & 1 & 6.6 \\
\hline 12 weeks & 2 & 13.3 \\
\hline 13 weeks & 1 & 6.6 \\
\hline 14 weeks & 1 & 6.6 \\
\hline
\end{tabular}

\section{Range of motion:}

\section{1- Extension:}

The range of extension was minimum -50 , maximum 15o. Patient reach extension range $<15 \mathrm{o}$ were $14(93.3 \%)$, > 15 o were $1(6.6 \%)$.

Table (2): Frequencies statistics of range of extension.

\begin{tabular}{|l|c|c|}
\hline \multicolumn{1}{|c|}{ Degree } & Frequency & Percent \\
\hline$<15 \mathrm{o}$ & 14 & $93.3 \%$ \\
\hline$>15 \mathrm{o}$ & 1 & $6.6 \%$ \\
\hline Total & 15 & $100 \%$ \\
\hline
\end{tabular}

\section{2- Flexion:}

The range of flexion was minimum 1150 , maximum 150o.patient reach flexion range < 120owere $1(6.6 \%)$, >120o were $14(93.3 \%)$.

Table (3): Frequencies statistics of range of extension.

\begin{tabular}{|c|c|c|}
\hline \multicolumn{1}{|c|}{ Degree } & Frequency & Percent \\
\hline$<120$ & 1 & $6.6 \%$ \\
\hline$>120$ & 14 & $93.3 \%$ \\
\hline Total & 15 & $100 \%$ \\
\hline
\end{tabular}

\section{Complications:}

Patients presented by complications as following: extension lag $1(6.6 \%)$, delayed union (healing at 3-6 months) 1 (6.6\%), and $13(86.6 \%)$ had no complications.

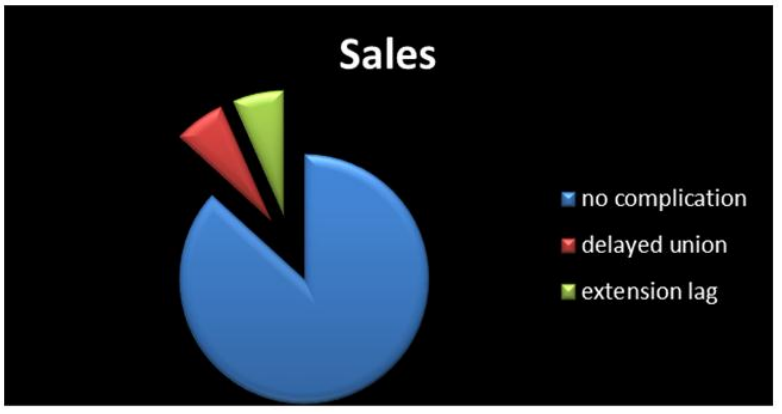

Figure (1): Percentage of complications.

According to classification of outcomes using the Hardacre criteria. 13 results $(86.6 \%)$ were excellent, two (13.3\%) were good.

Table (4): Frequencies statistics according to Hardacre criteria.

\begin{tabular}{|l|c|c|}
\hline \multicolumn{1}{|c|}{ Type } & Frequency & Percentage \\
\hline Excellent & 13 & $86.7 \%$ \\
\hline Good & 2 & $13.3 \%$ \\
\hline Poor & 0 & $0 \%$ \\
\hline Total & 15 & $100 \%$ \\
\hline
\end{tabular}

All cases were followed according to Mayo elbow score:

Table (5): Frequency statistics according to Mayo elbow score.

\begin{tabular}{|l|c|c|}
\hline \multicolumn{1}{|c|}{ Type } & Frequency & Percentage \\
\hline Excellent & 12 & $80 \%$ \\
\hline Good & 2 & $13.3 \%$ \\
\hline Fair & 1 & $6.6 \%$ \\
\hline Total & 15 & $100 \%$ \\
\hline
\end{tabular}

\section{DISCUSSION}

We compared our results with the results of the studies in literature, which used screw fixation in management of pediatric lateral condyle fracture.

Our results were similar to Gilberta et al. ${ }^{\text {(4); }}$ they showed statistically significant difference regarding complication rate and flexion range but no statistically significant difference regarding time to union.

In a study by $\mathbf{L i}$ and $\mathbf{X u}$ et al. ${ }^{(5)}$ reported the results of screw fixation (32 patients) they observed no significant difference in clinical outcome and no nonunion. They reported more frequent limitation of motion and a higher rate of infection. They observed clinically apparent lateral overgrowth in $12 \%$ of cases. They also observed that $19 \%$ of patients had apparent cubitus valgus. They reported more frequent limitation of motion and a higher rate of infection in the $\mathrm{K}$-wire group. They observed clinically apparent lateral overgrowth in $37 \%$ of patients treated with $\mathrm{K}$-wires 
and $12 \%$ of those treated with screws. They also observed differences in the carrying angle in $23 \%$ of patients treated with K-wires (six of seven of these appearing to have cubitus varus).

With regard to screw fixation, Loke $\boldsymbol{e t}$ al. ${ }^{(6)}$ examined 34 patients with an average follow-up of 24.5 months and found the average time to radiographic union to be 6.9 weeks. Excellent functional results were observed in $82 \%$. Lateral overgrowth was observed in two patients, lateral condylar avascular necrosis resulting in a valgus deformity in two patients, and a fishtail deformity in three patients.

In a study by Sharma et al. $^{(7)}$ followed up 37 children in whom $4.0 \mathrm{~mm}$ cancellous screws were placed, with a mean follow-up of 4.8 years. Painless, full range of motion was observed in 36 of the 37 patients. The one patient was observed to have a delayed union with loss of $10^{\circ}$ of elbow motion in comparison with the contralateral side. Mild fishtail deformity was also observed in three of the cases, but this was not observed to be functionally relevant. There was no instance of nonunion, avascular necrosis, or premature epiphyseal fusion.

In a study by Hasler and von Laer ${ }^{(8)}$ Studied 66 fractures, of which 27 were treated with screw placement. At a mean follow-up of 10 years, all 27 of the operative cases demonstrated anatomic union, symmetric carrying angles with the unaffected side, and full range of motion.

Results of K-wire fixation were reported by Boz et al. (9), who observed excellent functional results at an average follow-up of 39 months in $71.3 \%$ of 69 patients. Of the patients, $47 \%$ were observed to have lateral condylar overgrowth. Nonunion, however, was not observed in any patient.

In a study by Thomas et al. ${ }^{(10)}, 104$ patients underwent a 3-week period of K-wire fixation, with one instance of nonunion, two cases of infection, and a $44 \%$ incidence of abnormal elbow shape on late review (which included lateral condylar overgrowth and excessive bone formation over the outer surface of the condyle).

In a study by Skak $\boldsymbol{e t}$ al. ${ }^{(11)}$ describe the use of K-wire and Palmer nail fixation in 21 patients, reporting that all but one case was radiographically healed at a later review. It was documented that, in all of these patients, the distal humerus was wider in comparison with the unaffected side following healing. Two of these patients subsequently developed avascular necrosis of the trochlea.
Of 16 fractures treated with K-wire fixation by Jenyo and Mirdad ${ }^{(12)}$, malunion was observed in one case, resulting from loosening of a K-wire, and nonunion was observed in one case, requiring subsequent bone grafting and screw fixation.

In a study by Weiss et al. ${ }^{(13)}$ observed no nonunion and a $3.8 \%$ infection rate in the entire group of patients treated with K-wire fixation and 4 weeks of cast fixation. Among the 73 patients who had displacement requiring open reduction, nine had malunion, loss of reduction, or nonunion.

In another large series of 105 patients with $\mathrm{K}$-wire fixation following open reduction for displaced fractures, Leonidou $\boldsymbol{e t}$ al. ${ }^{(14)}$ reported $96 \%$ excellent results with no non-unions, no loss of motion and four patients with cubitus varus.

\section{CONCLUSION}

Surgeons currently treat lateral condyle fractures with K-wires or screws. Our study supports that screw fixation may be a viable option, with no non unions and fewer complications. These potential advantages have to be weighed against the need for subsequent screw removal and in some cases the screw direction changed as it crosses the olecranon fossa so we put it in lateral column of humerus that may affect rigidity of fixation. Longer follow-up will be required to assess effects on growth.

\section{REFERENCES}

1. Sharma H, Sibinski M, Sherlock DA (2009): Outcome of lateral humeral condylar mass fractures in children associated with elbow dislocation or olecranon fracture. Int Orthop., 33(2):509-514.

2. Milch H (1964): Fracture dislocations of the distal humeral condyles. J Trauma, 4:592-607.

3. Kiderlen MJ and Schlickewei W (2008): Operative procedures for intraarticular distal humerus fractures in children and adolescents. Operative Orthopadie und Traumatologie, 20(4-5): 423- 434.

4. Gilbert SR, MacLennan PA, Schlitz RS, Estes AR (2016): Screw versus pin fixation with open reduction of pediatric lateral condyle fractures. Journal of Pediatric Orthopaedics, 25(2): 148-152.

5. Li WC and Xu RJ (2012): Comparison of Kirschner wires and AO cannulated screw internal fixation for displaced lateral humeral 
condyle fracture in children. Int Orthop., 36:1261-1266.

6. Loke WP, Shukur MH, Yeap JK (2006): Screw osteosynthesis of displaced lateral humeral condyle fractures in children: a midterm review. Med J Malaysia, 61 (A):40-44.

7. Sharma JC, Arora A, Mathur NC, Gupta SP, Biyani A, Mathur R (1995): Lateral condyle fractures of the humerus in children: fixation with partially threaded $4.0 \mathrm{~mm} \mathrm{AO}$ cancellous screws. J Trauma, 39:1129-1133.

8. Hasler and von Laer, Froimson AI, Brown JE (1971): Fractures of the lateral condyle of the humerus in children. J Bone Joint Surg Am., 53:1083- 1095.

9. Boz V, Ulusal AE, Vuruskaner H, Aydinoglu Y (2005): Functional results of displaced lateral condyle fractures of the humerus with 4 week K-wire fixation in children. Acta Orthop Trauamatol Turc., 39:193-198.

10. Thomas DP, Howard AW, Cole WG, Hedden DM (2001): Three weeks of K-wire fixation for displaced lateral condyle fractures of the humerus in children. J Pediatr Orthop., 21:565-569.

11. Skak SV, Olsen SD, Smaabrekke A (2001): Deformity after fracture of the lateral humeral condyle in children. J Pediatr Orthop., 10:142152.

12. Jenyo $M$ and Mirdad $T$ (2001): Fractures of the lateral condyle of the humerus in children. East Afr Med J., 78:424-429.

13. Weiss JM, Graves S, Yang S, Mendlesohn E, Kay RM, Skaggs DL (2009): A new classification system predictive of complications in surgically treated pediatric humeral lateral condyle fractures. J Pediatr Orthop., 29:602- 605.

14. Leonidou A, Chettiar K, Graham S, Akhbari P, Antonis K, Tsiridis E, Leonidou O (2014): Open reduction internal fixation of lateral humeral condyle fractures in children. A series of 105 fractures from a single institution. Strategies Trauma Limb Reconstr., 9:73-78. 